\title{
Calculation Model of Relative Permeability in Tight Sandstone Gas Reservoir with Stress Sensitivity
}

\author{
Jin Yan, ${ }^{1}$ Rongchen Zheng, ${ }^{1}$ Peng Chen $\mathbb{D}^{1,2}$ Shuping Wang, ${ }^{1}$ and Yunqing Shi ${ }^{1}$ \\ ${ }^{1}$ State Key Laboratory of Shale Oil and Gas Enrichment Mechanisms and Effective Development, Beijing 100083, China \\ ${ }^{2}$ School of Geosciences, Yangtze University, Hubei, Wuhan 430100, China \\ Correspondence should be addressed to Peng Chen; ccpeng2008@126.com
}

Received 6 September 2021; Revised 3 November 2021; Accepted 24 November 2021; Published 10 December 2021

Academic Editor: Jinjie Wang

Copyright ( 2021 Jin Yan et al. This is an open access article distributed under the Creative Commons Attribution License, which permits unrestricted use, distribution, and reproduction in any medium, provided the original work is properly cited.

\begin{abstract}
During the development of tight gas reservoir, the irreducible water saturation, rock permeability, and relative permeability change with formation pressure, which has a significant impact on well production. Based on capillary bundle model and fractal theory, the irreducible water saturation model, permeability model, and relative permeability model are constructed considering the influence of water film and stress sensitivity at the same time. The accuracy of this model is verified by results of nuclear magnetic experiment and comparison with previous models. The effects of some factors on irreducible water saturation, permeability, and relative permeability curves are discussed. The results show that the stress sensitivity will obviously reduce the formation permeability and increase the irreducible water saturation, and the existence of water film will reduce the permeability of gas phase. The increase of elastic modulus weakens the stress sensitivity of reservoir. The irreducible water saturation increases, and the relative permeability curve changes little with the increase of effective stress. When the minimum pore radius is constant, the ratio of maximum pore radius to minimum pore radius increases, the permeability increases, the irreducible water saturation decreases obviously, and the two-phase flow interval of relative permeability curve increases. When the displacement pressure increases, the irreducible water saturation decreases, and the interval of two-phase flow increases. These models can calculate the irreducible water saturation, permeability and relative permeability curves under any pressure in the development of tight gas reservoir. The findings of this study can help for better understanding of the productivity evaluation and performance prediction of tight sandstone gas reservoirs.
\end{abstract}

\section{Introduction}

With more and more tight gas reservoirs are put into development around the world, tight gas reservoirs have become an important part of the current natural gas production. Tight sandstone gas is an unconventional natural gas resource, which exists in tight sandstone reservoirs, and its permeability is generally less than $0.1 \mathrm{mD}$ [1-3]. Such reservoirs generally have no natural capacity or extremely low capacity, and they can only be exploited under certain economic and technical conditions. Because most of tight sandstone gas reservoirs are firstly tight and then accumulate, they have obvious characteristics of near-source accumulation. Due to the influence of factors such as sedimentation, accumulation, and reservoir physical properties, the occurrence state of formation water is diverse in tight gas reser- voirs. In the production process, gas well produces water, which severely restricts the benefit of gas reservoir development $[4,5]$. In addition, the reservoir is prone to stresssensitive effects, which results in a rapid decline. Therefore, it is necessary to study the change characteristics of permeability and relative permeability curve during the development of tight sandstone gas reservoirs.

When the effective stress is increased in tight gas reservoirs, the pores will undergo elastic and plastic deformation, and the stress-sensitive effect will cause the porosity and permeability to decrease. Many scholars have studied the mechanism of reservoir stress sensitivity through physical simulation methods [6-10]. These experimental results show that the permeability decreases significantly and the porosity changes little with the increase of confining pressure [10-12]. These physical simulation experiments are 
only suitable for research on specific objects under given conditions and cannot reflect the change characteristics of reservoir physical properties during the development of gas reservoir. On the basis of rock mechanics, some scholars construct a mathematical model of permeability changing with confining pressure and have realized effective prediction of permeability during the decrease of reservoir pressure $[13,14]$. Through experimental data fitting, some scholars have constructed the relationship model between permeability and effective stress, which mainly include exponential model, logarithmic model, and linear relationship model [15-17]. These models based on experimental data only reveal the relationship between permeability and effective stress and do not reflect the mechanism of stress-sensitive effects. Based on the theory of elastic mechanics, some models are established to describe the mechanism of stress sensitivity. Cao and Lei establish a permeability model in tight reservoirs, which considers the stress sensitivity based on the Hertz contact deformation principle [18]. Xu constructs digital core samples with different porosity and different pore size distributions by the four-parameter random growth model and gives a permeability model using elastic mechanics theory [19]. Although the above models can calculate the formation permeability, it is not suitable for multiphase fluids and cannot obtain the relative permeability curve of two-phase flow. At present, most gas-water phase relative permeability curves are obtained through core experiments. Due to the limitation of experimental conditions, the measured relative permeability curve cannot simulate the characteristics of two-phase flow after stress sensitivity in tight reservoirs $[20,21]$. Some scholars establish two-phase relative permeability calculation models based on different methods. Yan et al. constructs the permeability model and the relative permeability model using numerical core technology and lattice Boltzmann method, which can calculate the core relative permeability curve by $T_{2}$ spectrum, but these methods cannot be used in stresssensitive reservoirs [22]. Based on the capillary bundle model and fractal theory, Lei et al. construct a two-phase flow model considering stress sensitivity, but the model does not consider the influence of water film in a tight sandstone gas reservoir [23]. Due to the hydrophilicity of formation, bound water films are widespread in tight sandstone gas reservoirs [24]. Derjaguin and Churaev use DLVO theory to establish a thickness model of fluid film and explain the influence factors of water film thickness [24]. Su et al. use the capillary bundle model and the fractal theory to establish the irreducible water saturation calculation model with the influence of stress sensitivity and analyze the influence of water film thickness on the irreducible water saturation of tight reservoirs [25].

The above studies show that water film and stresssensitive effect are common in tight reservoirs and have a significant impact on the fluid flow capacity (Figure 1). At present, only one of them is considered in some calculation models of permeability and relative permeability in tight reservoirs, and it is urgent to establish relevant mathematical models considering both water film and stress sensitivity. Based on the capillary bundle model and the fractal theory, this paper constructs a model of irreducible water saturation under the given pressure differences and gives a permeability model and a calculation model of relative permeability curve considering the stress sensitivity and water film in tight sandstone gas reservoirs. These models are used to discuss the influence of some factors on irreducible water saturation, permeability, and relative permeability curve.

\section{Mathematical Model}

2.1. Model of Irreducible Water Saturation. In nature, both the part and the whole of an object have self-similarity, which conforms to the principle of fractal. In tight sandstone reservoirs, the pore structure also has fractal characteristics, and the size distribution of pore can be characterized as follows [26]:

$$
N(r)=\int_{r}^{r_{\max }} f(r) d r=\left(\frac{r_{\max }}{r}\right)^{D_{f}},
$$

where $N(r)$ is the capillary number, $r$ is the radius of capillary, $r_{\max }$ is the maximum radius of capillary, $f(r)$ is the distribution function of capillary bundle, and $D_{f}$ is the pore area fractal dimension.

By deriving from the above formula, the expression of capillary bundle quantity function $f(x)$ can be obtained as follows:

$$
f(r)=D_{f} r_{\max }^{D_{f}} r^{-D_{f}-1}
$$

According to the rock characteristics of tight reservoirs and the fractal principle, the fractal dimension $D_{f}$ can be written as [26]

$$
D_{f}=d-\frac{\ln \phi}{\ln \left(r_{\min } / r_{\max }\right)},
$$

where $d$ is the Euclidean dimension, $d=2$ in twodimensional space. $\phi$ is the porosity, and $r_{\min }$ is the minimum radius of capillary.

The core is simplified as a capillary bundle model. Due to the certain curvature of the pore in the core, the length of capillary bundle is generally greater than the apparent length. According to the fractal theory, there is selfsimilarity between the actual length and the characteristic length of capillary bundle, and the actual length of capillary bundle can be expressed as [26]

$$
L(r)=(2 r)^{1-D_{T}} L_{0}^{D_{T}}
$$

where $D_{t}$ is the tortuosity fractal dimension, and it is [26]

$$
D_{T}=1+\frac{\ln \bar{\tau}}{\ln \left(L_{0} / 2 \bar{r}\right)},
$$




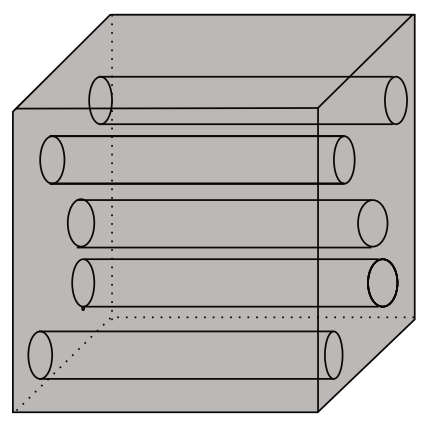

(a) Capillary bundle model

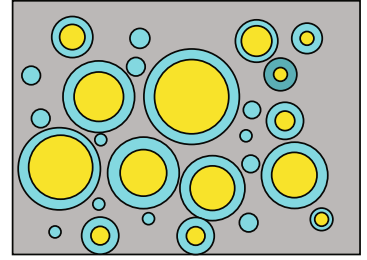

Solid phase

Gas phase

Water phase

(b) Capillary bundle without stress sensitivity

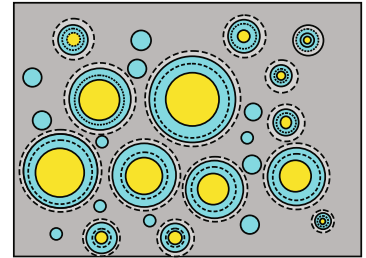

Solid phase

Gas phase

Water phase

(c) Capillary bundle with stress sensitivity

FIgURE 1: The distribution of gas and water in capillary bundle model [25].

where $\bar{\tau}$ is the average tortuosity, and $L_{0}$ is the capillary characteristic length. They can be written as $[27,28]$

$$
\bar{\tau}=\frac{1}{2}\left[1+\frac{1}{2} \sqrt{1-\phi}+\frac{\sqrt{(1-\sqrt{1-\phi})^{2}+0.25(1-\phi)}}{1-\sqrt{1-\phi}}\right],
$$

$\frac{L_{0}}{2 \bar{r}}=\frac{D_{f}-1}{\sqrt{D_{f}}} \sqrt{\frac{1-\phi}{4 \phi} \frac{\pi}{2-D_{f}}} \frac{r_{\max }}{r_{\min }}$.

Regarding the core as a capillary bundle model, the bound water includes the immovable water in the thin capillary tubes and the water film retained water in the general capillary tubes. Immovable water in the thin capillary tubes mainly refers to the water that does not flow in these capillaries when the displacement pressure is less than the capillary pressure. In general, due to the hydrophilicity of rocks and minerals, a layer of water film is produced on the wall of wide capillary tubes. The irreducible water saturation is the sum of immovable water saturation and water film retention water saturation, which can be written as

$$
S_{w c}=S_{w n}+S_{w f},
$$

where $S_{w c}$ is the irreducible water saturation, $S_{w n}$ is the immovable water saturation in fine capillaries, and $S_{w f}$ is the water saturation of water film.

In thin capillaries, the water cannot flow due to the capillary force, and the capillary is completely saturated with water. According to the capillary bundle model and the fractal principle, the water content volume in the part of capillary bundle can be written as

$$
\begin{aligned}
V_{w n} & =\int_{r_{\min }}^{r_{\max }} \pi r^{2} L(r) f(r) d r-\int_{r_{c}}^{r_{\max }} \pi r^{2} L(r) f(r) d r \\
& =\int_{r_{\min }}^{r_{c}} \pi r^{2} L(r) f(r) d r,
\end{aligned}
$$

where $V_{w n}$ is the immovable water volume in fine capillaries, and $r_{c}$ is the minimum flow pore radius under a certain dis- placement pressure in the capillary bundle model. The capillary force in the capillary is equal to the displacement pressure, which can be expressed as

$$
r_{c}=\frac{2 \sigma \cos \theta}{p_{d}},
$$

where $\sigma$ is the interfacial tension, $\theta$ is the wetting angle, and $p_{d}$ is the displacement pressure.

The interfacial tension is affected by factors such as temperature, pressure, fluid composition, and other factors. For the gas-water interfacial tension, the calculation formula is [29]

$$
\sigma=\frac{1.8(137.78-T)}{206}[\sigma(23.33)-\sigma(137.78)]+\sigma(137.78),
$$

where $T$ is the temperature, $\sigma(23.33)=76 \exp (-0.0362575$ $p), \sigma(137.78)=52.5-0.87018 p$.

In thick capillaries, the surface of pores is covered by a layer of water film. Li et al. analyze by microtube experiments that the thickness of water film has a linear relationship with fluid viscosity and a power function relationship with capillary radius. The water film thickness formula can be expressed as [25]

$$
\delta= \begin{cases}r \times 0.25763 e^{-0.261 r}(\nabla p)^{-0.419} \mu_{w} & \nabla p<1 \mathrm{MPa} / \mathrm{m}, \\ r \times 0.25763 e^{-0.261 r} \mu_{w} & p>1 \mathrm{MPa} / \mathrm{m},\end{cases}
$$

where $\delta$ is water film thickness, $\nabla p$ is the pressure gradient, and $\mu$ is the viscosity of water.

Since the viscosity of water is mainly affected by temperature, relevant scholars have given the relationship between viscosity and temperature [30]:

$\mu_{w}=0.001792 \exp \left[-1.94-4.8 \frac{273.15}{T}+6.74\left(\frac{273.15}{T}\right)^{2}\right]$. 
In a capillary with water film, the retained water volume of water film is equal to the total volume of capillary minus the gas filling volume, which can be expressed as

$$
V_{w f}=\int_{r_{c}}^{r_{\max }} \pi\left[r^{2}-(r-\delta)^{2}\right] L(r) f(r) d r
$$

where $V_{w f}$ is the water volume of water film.

The volume of total bound water in a capillary bundle model is

$$
\begin{aligned}
V_{w c} & =V_{w n}+V_{w f} \\
& =\int_{r_{\min }}^{r_{c}} \pi r^{2} L(r) f(r) d r+\int_{r_{c}}^{r_{\max }} \pi\left[r^{2}-(r-\delta)^{2}\right] L(r) f(r) d r .
\end{aligned}
$$

The irreducible water saturation in the capillary bundle model is the ratio of the total irreducible water volume to the pore volume, which can be expressed as

$$
\begin{aligned}
S_{w c} & =\frac{V_{w n}+V_{w f}}{V_{p}} \\
& =\frac{\int_{r_{\text {min }}}^{r_{c}} \pi r^{2} L(r) f(r) d r+\int_{r_{c}}^{r_{\max }} \pi\left[r^{2}-(r-\delta)^{2}\right] L(r) f(r) d r}{\int_{r_{\text {min }}}^{r_{\text {max }}} \pi r^{2} L(r) f(r) d r},
\end{aligned}
$$

where $V_{p}$ is the pore volume.

2.2. Model of Irreducible Water Saturation with Stress Sensitivity. In the development of gas reservoirs, the decrease of formation pressure will lead to pore compression, pore radius reduces, and rock permeability decreases. According to Hertzian contact theory, the relationship between capillary radius and effective stress is as follows [31]:

$$
r^{\prime}=r\left\{1-4\left[\frac{3 \pi\left(1-v^{2}\right) p_{e f f}}{4 E}\right]^{\beta}\right\}
$$

where $E$ is the elastic modulus, $v$ is the Poisson's ratio, $\beta$ is a constant, and the superscript "is the relevant parameters after stress sensitivity.

After the stress sensitivity effect occurs, the pore volume of capillary bundle model will change, the model constructed by Harari characterizes the relationship between porosity and effective stress, and it is written as [32]

$$
\phi^{\prime}=1.09 \phi p_{e f f}^{-0.0152} .
$$

According to equations (17) and (18), the porosity and radius of rock will decrease after the stress-sensitive effect occurs. The pore area fractal dimension with stress sensitivity effect can be written as

$$
D_{f}^{\prime}=d-\frac{\ln \phi^{\prime}}{\ln \left(r_{\min }^{\prime} / r_{\max }\right)} .
$$

The tortuosity fractal dimension with stress sensitivity effect can be expressed as

$$
D_{T}^{\prime}=1+\frac{\ln \bar{\tau}^{\prime}}{\ln \left(L_{0}^{\prime} / 2 \bar{r}^{\prime}\right)}
$$

where $\bar{\tau}^{\prime}$ and $L_{0}^{\prime} / 2 \bar{r}^{\prime}$ can be written as

$$
\bar{\tau}^{\prime}=\frac{1}{2}\left[1+\frac{1}{2} \sqrt{1-\phi^{\prime}}+\frac{\sqrt{\left(1-\sqrt{1-\phi^{\prime}}\right)^{2}+0.25\left(1-\phi^{\prime}\right)}}{1-\sqrt{1-\phi^{\prime}}}\right]
$$

$\frac{L_{0}^{\prime}}{2 \bar{r}^{\prime}}=\frac{D_{f}^{\prime}-1}{\sqrt{D_{f}^{\prime}}} \sqrt{\frac{1-\phi^{\prime}}{4 \phi^{\prime}} \frac{\pi}{2-D_{f}^{\prime}} \frac{r_{\max }}{r_{\min }}}$.

The volume of bound water is the sum of the volume of water in the thin capillaries after radius changes and the volume of formation water in the thick capillaries, which can be expressed as

$$
V_{w c}^{\prime}=\int_{r_{\min }^{\prime}}^{r_{c}} \pi r^{2} L^{\prime}(r) f^{\prime}(r) d r+\int_{r_{c}}^{r_{\max }^{\prime}} \pi\left[r^{2}-(r-\delta)^{2}\right] L^{\prime}(r) f^{\prime}(r) d r .
$$

After the formation pressure drops, the irreducible water saturation is equal to the ratio of irreducible water saturation to the changed pore volume, so it is

$S_{w c}^{\prime}=\frac{\int_{r_{\min }^{\prime}}^{r_{c}} \pi r^{2} L^{\prime}(r) f^{\prime}(r) d r+\int_{r_{c}}^{r_{\max }^{\prime}} \pi\left[r^{2}-(r-\delta)^{2}\right] L^{\prime}(r) f^{\prime}(r) d r}{\int_{r_{\min }^{\prime}}^{r_{\max }^{\prime}} \pi r^{2} L^{\prime}(r) f^{\prime}(r) d r}$.

The formation water will expand due to its elastic energy, and its elastic compressibility can be expressed as [33]

$$
C_{w}=145.03 \times 10^{-6}\left(a+b+c^{2}\right),
$$

where $C_{w}$ is the elastic compressibility of water, $a, b$, and $c$ are the coefficients, and they can be written as

$$
\begin{aligned}
& a=3.8546-1.9435 \times 10^{-2} p, \\
& b=-0.01052+6.9179 \times 10^{-5} p, \\
& c=3.9267 \times 10^{-5}-1.2763 \times 10^{-7} p .
\end{aligned}
$$


After the formation pressure drops, the volume of movable water is equal to the volume of formation water after hydro elastic expansion minus the volume of bound water. It is written as

$$
\Delta V_{w}=\left(1+C_{w} \Delta p\right) V_{w}-V_{w c}^{\prime}
$$

where $\Delta V_{w}$ is the increased volume of movable water after stress sensitivity, and $\Delta p$ is the pressure drop.

The movable water saturation can be expressed as

$$
\Delta S_{w}=\frac{\left(1+C_{w} \Delta p\right) V_{w}-V_{w c}^{\prime}}{\int_{r_{\min }^{\prime}}^{r_{\max }^{\prime}} \pi r^{2} L^{\prime}(r) f^{\prime}(r) d r} .
$$

2.3. Permeability Model. In the capillary bundle, it is assumed that the pressure difference at both ends of the capillary bundle is $\Delta p$, and according to Poiseuille's law, the fluid flow in a single capillary bundle is

$$
q=\frac{\pi r^{4} \Delta p}{8 \mu L(r)}
$$

where $q$ is the flow of single capillary.

The total flow of the core is the sum of all capillary flows in the capillary bundle model. The flow can be expressed as

$$
\begin{aligned}
Q & =\int_{r_{\min }}^{r_{\max }} \frac{\pi r^{4} \Delta p}{8 \mu L(r)} f(r) d r \\
& =\int_{r_{\min }}^{r_{\max }} \frac{\pi r^{4} \Delta p}{8 \mu(2 r)^{1-D_{T}} L_{0}^{D_{T}}} D_{f} r_{\max }^{D_{f}} r^{-D_{f}-1} d r \\
& =\frac{\pi D_{f} r_{\max }\left(r_{\max }^{3+D_{T}-D_{f}}-r_{\min }^{3+D_{T}-D_{f}}\right)}{8 \mu \times 2^{1-D_{T}} L_{0}^{D_{T}}\left(3+D_{T}-D_{f}\right)} \Delta p,
\end{aligned}
$$

where $Q$ is the total flow of capillary bundle model.

According to Darcy's law, the flow can be expressed as

$$
Q=\frac{K A \Delta p}{\mu L},
$$

where $K$ is the permeability, and $A$ is the cross-sectional area.

By introducing equation (32) in equation (33), the permeability of rock can be calculated. The permeability can be expressed as

$$
K=\frac{2^{D_{T}} \pi D_{f} r_{\max }^{D_{f}}\left(r_{\max }^{3+D_{T}-D_{f}}-r_{\min }^{3+D_{T}-D_{f}}\right)}{16 A L_{0}^{D_{T}-1}\left(3+D_{T}-D_{f}\right)}
$$

According to the fractal principle, there are

$$
A=\frac{\pi D_{f} r_{\max }^{2}}{\phi\left(2-D_{f}\right)}, L_{0}=\sqrt{A}=\sqrt{\frac{\pi D_{f} r_{\max }^{2}}{\phi\left(2-D_{f}\right)}} .
$$

Stress sensitivity is common in tight reservoirs. After the stress sensitivity occurs, the porosity and radius will decrease, and its permeability will also decrease. Considering the influence of stress-sensitivity effect, the permeability expression can be written as

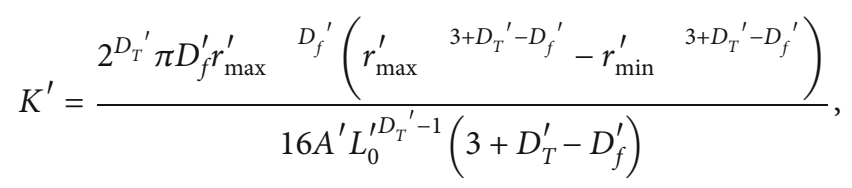

where the cross-sectional area $A^{\prime}$ and the capillary characteristic length $L_{0}^{\prime}$ with stress sensitivity can be expressed as

$$
A^{\prime}=\frac{\pi D_{f}^{\prime} r_{\max }^{\prime 2}}{\phi^{\prime}\left(2-D_{f}^{\prime}\right)}, L_{0}^{\prime}=\sqrt{A^{\prime}}=\sqrt{\frac{\pi D_{f}^{\prime} r_{\max }^{\prime 2}}{\phi^{\prime}\left(2-D_{f}^{\prime}\right)}}
$$

2.4. Relative Permeability Model. As a flow capacity curve describing multiphase fluid flowing in rock core at the same time, relative permeability curve is widely used in the development of oil and gas reservoirs. Many scholars study the relative permeability curve by mathematical model and physical simulation experiment [33-37]. Tsakiroglou proposes the analytical solution of the relative permeability by network simulations in porous reservoirs [38]. Based on the fractal theory, a relative permeability model is built in fracture networks, which is a function of saturation of water and gas [39]. Based on percolation theory and effective medium theory in, a model of two-phase permeability curve is established using the bimodal fractal model [40]. These studies provide a good idea for the application of fractal theory in relative permeability curve, but they do not consider the influence the water film and stress-sensitive effect. In tight gas reservoir, water film and stress-sensitive effect have an obvious influence on gas flow, and it is necessary to establish a calculation model of relative permeability.

Considering the influence of water film thickness on gas flow, the flow radius is equal to the pore radius minus the water film thickness. The permeability of gas phase and water phase can be calculated by Poiseuille's law and Darcy's law, and they can be written as [23]

$$
\begin{gathered}
K_{g}=\frac{2^{D_{T}} \pi\left(1-S_{w}\right) D_{f} r_{\max }^{D_{f}}}{16 A L_{0}^{D_{T}-1}} \int_{r_{w g c}}^{r_{\max }}(r-\delta)^{2+D_{T}-D_{f}} d r, \\
K_{w}=\frac{2^{D_{T}} \pi S_{w} D_{f} r_{\max }^{D_{f}}}{16 A L_{0}^{D_{T}-1}} \int_{r_{c}}^{r_{w g c}}(r-\delta)^{2+D_{T}-D_{f}} d r,
\end{gathered}
$$

where $K_{g}$ is the permeability of gas phase, $K_{w}$ is the permeability of water phase, and $S_{w}$ is the water saturation.

Relative permeability is the ratio of phase permeability to inherent permeability, simultaneous equations (34), (38), 
TABLE 1: Comparison of results between core experiment and model.

\begin{tabular}{|c|c|c|c|c|c|c|c|c|c|c|}
\hline \multirow{2}{*}{ Well } & \multirow{2}{*}{ Depth (m) } & \multirow{2}{*}{ Length $(\mathrm{cm})$} & \multirow{2}{*}{ Diameter $(\mathrm{cm})$} & \multirow{2}{*}{ Porosity } & \multicolumn{2}{|c|}{$\begin{array}{l}\text { Irreducible water } \\
\text { saturation }\end{array}$} & \multirow[b]{2}{*}{ Error (\%) } & \multicolumn{3}{|c|}{ Permeability } \\
\hline & & & & & Experiment & Model & & Experiment & Model & Error (\%) \\
\hline \multirow{4}{*}{ D16 } & \multirow{4}{*}{2868} & \multirow{4}{*}{2.832} & \multirow{4}{*}{2.534} & \multirow{4}{*}{7.85} & 0.4471 & 0.4624 & 3.42 & \multirow{4}{*}{0.3228} & \multirow{4}{*}{0.3316} & \multirow{4}{*}{2.73} \\
\hline & & & & & 0.4166 & 0.3977 & 4.53 & & & \\
\hline & & & & & 0.3503 & 0.3467 & 1.02 & & & \\
\hline & & & & & 0.2917 & 0.2976 & 2.03 & & & \\
\hline \multirow{4}{*}{ D22 } & \multirow{4}{*}{2773} & \multirow{4}{*}{2.153} & \multirow{4}{*}{2.542} & \multirow{4}{*}{7.14} & 0.5126 & 0.5152 & 0.51 & \multirow{4}{*}{0.2328} & \multirow{4}{*}{0.2553} & \multirow{4}{*}{9.66} \\
\hline & & & & & 0.4384 & 0.4451 & 1.54 & & & \\
\hline & & & & & 0.3655 & 0.3936 & 7.69 & & & \\
\hline & & & & & 0.3277 & 0.3424 & 4.49 & & & \\
\hline
\end{tabular}

and (39), and the relative permeability of gas phase and water phase can be expressed as

$$
\begin{aligned}
& K_{r g}=\frac{K_{g}}{K}=\left(1-S_{w}\right)\left(3+D_{T}-D_{f}\right) \frac{\int_{r_{w g c}}^{r_{\max }}(r-\delta)^{2+D_{T}-D_{f}} d r}{r_{\max }^{3+D_{T}-D_{f}}-r_{\min }^{3+D_{T}-D_{f}}}, \\
& K_{r w}=\frac{K_{w}}{K}=S_{w}\left(3+D_{T}-D_{f}\right) \frac{\int_{r_{c}}^{r_{w g}}(r-\delta)^{2+D_{T}-D_{f}} d r}{r_{\max }^{3+D_{T}-D_{f}}-r_{\min }^{3+D_{T}-D_{f}}},
\end{aligned}
$$

where $K_{r g}$ is the relative permeability of gas phase, and $K_{r w}$ is the relative permeability of water phase.

After the occurrence of stress sensitivity, the pore structure changes and relevant parameters change, but the calculation principle of relative permeability remains unchanged. The relative permeability of gas phase and water phase can be expressed as

$$
K_{r g}^{\prime}=\frac{K_{g}^{\prime}}{K^{\prime}}=\left(1-S_{w}^{\prime}\right)\left(3+D_{T}^{\prime}-D_{f}^{\prime}\right)_{1} \frac{\int_{r_{w g c}^{\prime}}^{r_{\max }^{\prime}}(r-\delta)^{2+D_{T}{ }^{\prime}-D_{f}{ }^{\prime}} d r}{r_{\max }^{3+D_{T}{ }^{\prime}-D_{f}{ }^{\prime}-}{ }^{\prime} r_{\min }{ }^{3+D_{T}{ }^{\prime}-D_{f}{ }^{\prime}}},
$$

$$
K_{r w}^{\prime}=\frac{K_{w}^{\prime}}{K^{\prime}}=S_{w}^{\prime}\left(3+D_{T}^{\prime}-D_{f}^{\prime}\right)_{1} \frac{\int_{r_{c}^{\prime}}^{r_{w g c}^{\prime}}(r-\delta)^{2+D_{T}{ }^{\prime}-D_{f}{ }^{\prime} d r}}{r_{\max }{ }^{3+D_{T}{ }^{\prime}-D_{f}{ }^{\prime}}-r_{\min }{ }^{3+D_{T}{ }^{\prime}-D_{f}{ }^{\prime}}} .
$$

\section{Model Validation}

Nuclear magnetic resonance experiments can test the distribution characteristics of water in different pores. According to test results under different displacement pressures, the distribution of water saturation in rocks under different displacement pressures can be obtained. The irreducible water saturation of two cores under different displacement pressure is tested by nuclear magnetic resonance experiments, and the related parameters and experimental results are shown in Table 1. At the same time, the maximum pore radius, the minimum pore radius, and the ratio between them can be calculated using the $T_{2}$ spectrum curve. Based on the proposed irreducible water saturation model and permeability model, the water saturation and permeability of the core under different pressure can be obtained according to these characteristic parameters (Table 1). Comparing the irreducible water saturation and permeability calculated by the model with the core test results, it is found that the maximum error of the irreducible water saturation under different displacement pressure is $7.69 \%$, the minimum error is 0.51 , and the average is $3.15 \%$. The maximum error of the permeability is $9.66 \%$, the minimum error is $2.73 \%$, and the average is $6.2 \%$. The results of these models and the experimental results have relatively small errors, and these models can be used to predict irreducible water saturation and permeability under different displacement pressures.

This paper also gives a relative permeability model based on the fractal principle. The relative permeability curve calculated by the model is compared with the results of Li's model and Lei's model $[23,24]$. In the calculation, the porosity is 0.2 , the irreducible water saturation is 0.24 , and the ratio of the maximum pore radius to the minimum pore radius is 100 . The results show that the model is basically similar to the results of Li's model and Lei's model (Figure 2). The relative permeability of gas phase in this model is slightly lower than that of Lei's model without considering water film, indicating that the existence of water film has a certain influence on relative permeability curve. The relative permeability model proposed in this paper can meet the needs of practical applications.

\section{Analysis and Discussion}

In the section, the relevant parameters under given conditions are calculated by using the irreducible water saturation model, permeability model, and relative permeability model. The effects of rock elastic modulus, Poisson's ratio, the ratio of maximum pore radius to minimum pore radius, and minimum flowable pore radius on irreducible water saturation, permeability, and relative permeability are discussed.

4.1. Elastic Modulus. Elastic modulus is one of basic parameters to measure elastic deformation of rock, and its value 


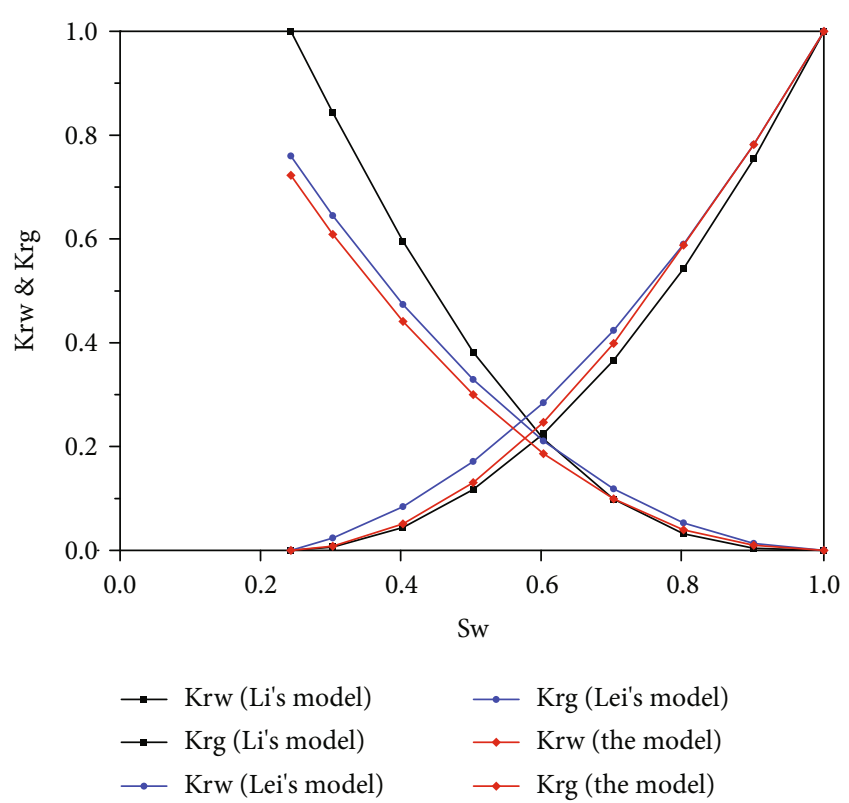

FIGURE 2: Results comparison of different relative permeability models with this model.

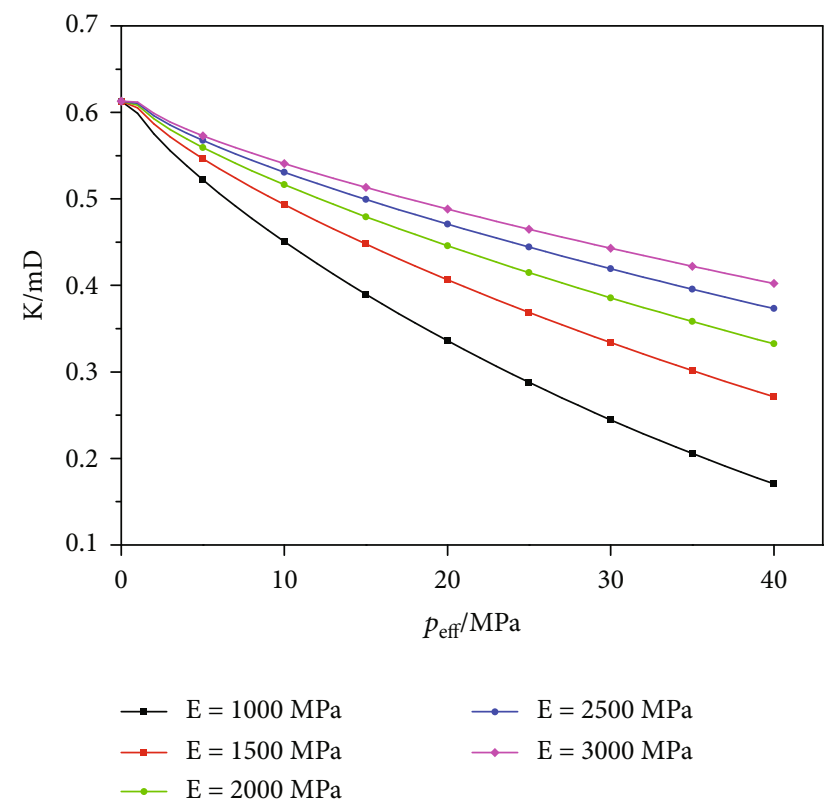

FIGURE 3: Relationship curve between permeability and effective stress under different elastic modulus.

reflects the degree of compressibility. When effective stress is certain, the larger the elastic modulus is, and the smaller the compressibility of rock is. Figure 3 shows the relationship between permeability and effective stress under different elastic modulus. With the increase of elastic modulus, the elasticity decreases, and the deformation amplitude of pore radius under the same effective stress decreases. Therefore, the larger the elastic modulus is, the larger the permeability retention value is. Figure 4 is the relationship between irreducible water saturation and effective stress under different elastic modulus. With the increase of elastic modulus, irre-

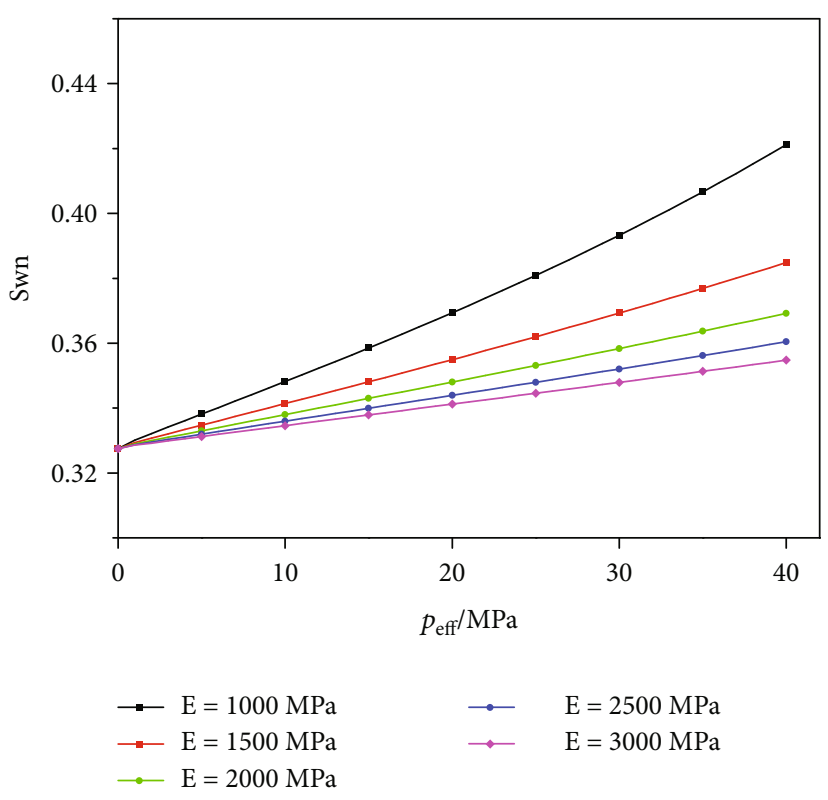

FIgURE 4: Relationship curve between irreducible water saturation and effective stress under different elastic modulus.

ducible water saturation decreases. This is due to the increase of elastic modulus, the number of nonflowing capillaries decreases under the same stress, so the irreducible water saturation decreases. When the effective stress increases, capillaries with radius less than the minimum flowable pore radius increase, and the irreducible water saturation increases. When the elastic modulus and effective stress changes in the capillary bundle, the capillary radius changes little. While the relative permeability curve mainly reflects the structural characteristics in the pore, the relative permeability curve changes little (Figure 5).

4.2. Poisson's Ratio. Poisson's ratio is other basic parameters to measure elastic deformation of rock, which represents the ratio of transverse strain to axial strain. Figure 6 is the relationship curve between permeability and effective stress under different Poisson's ratios. Poisson's ratio has little effect on rock permeability. With the increase of Poisson's ratio, the permeability increases to a certain extent, but the increase is very small, which indicates that the size of Poisson's ratio has little effect on the elastic compression of rock pores. Figure 7 shows the relationship curve between irreducible water saturation and effective stress under different Poisson's ratios. Since Poisson's ratio has little effect on elastic compression of rock pores, Poisson's ratio has little effect on irreducible water saturation. With the increase of Poisson's ratio, irreducible water saturation decreases slightly under the same effective stress, and Poisson's ratio has little effect on relative permeability curve.

4.3. Ratio of Maximum Pore Radius to Minimum Pore Radius. When the porosity and minimum pore radius are certain, the ratio of maximum pore radius to minimum pore radius represents the pore scale distribution interval. The larger the pore distribution interval is, the larger the radius 


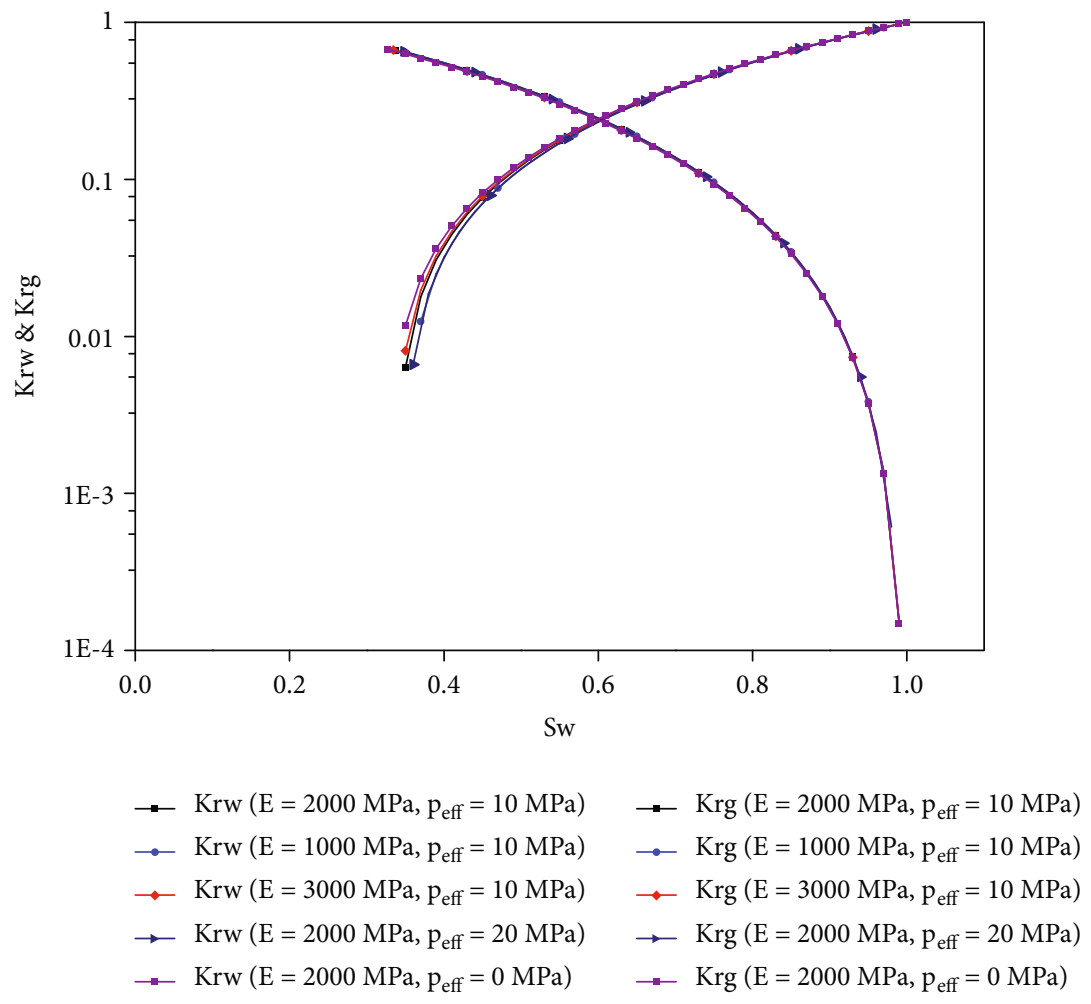

FIgURE 5: Relative permeability curve under different elastic modulus and effective stress.

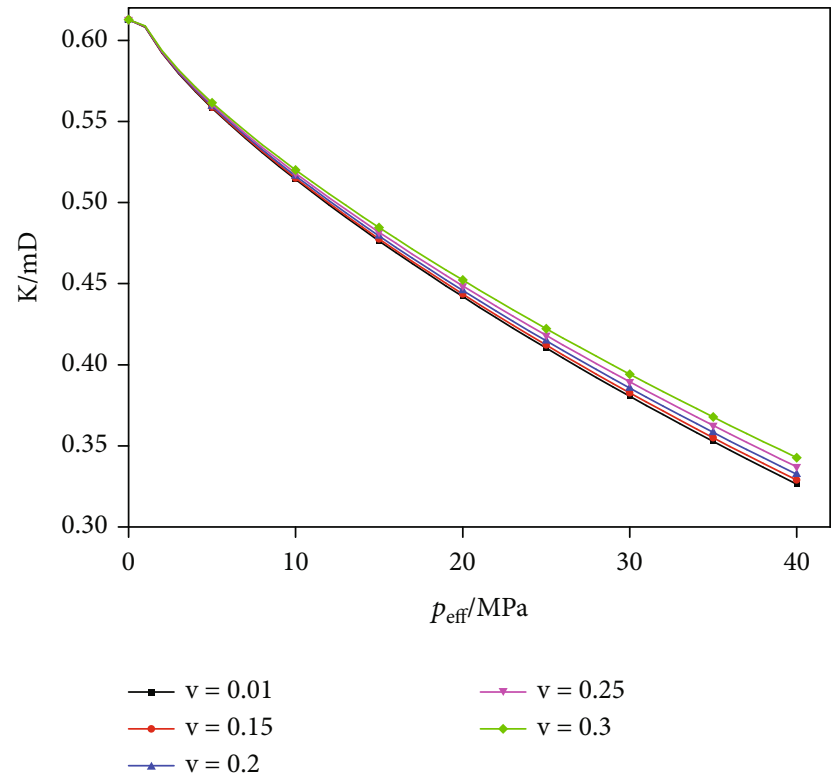

Figure 6: Relationship curve between permeability and effective stress under different Poisson's ratio.

of pores is in rock, and the flow capacity is enhanced, so the permeability is increased (Figure 8). The smaller the ratio of the maximum pore radius to the minimum pore radius is, this means that the pore radius is concentrated in the minimum pore radius' accessories. When the displacement pressure is constant, the minimum capillary radius which can be driven is a certain value, the more

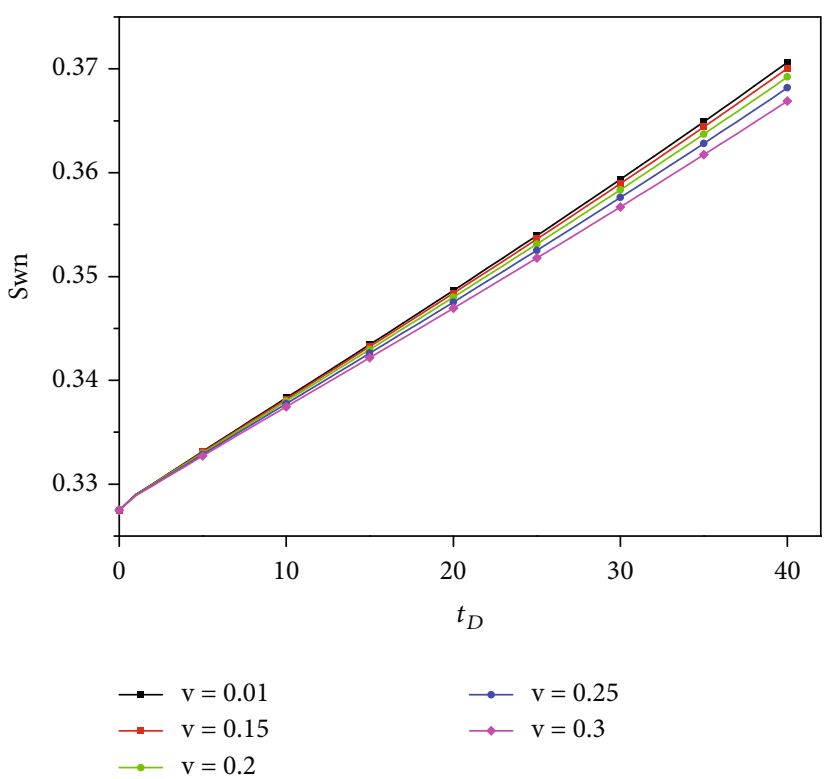

FIGURE 7: Relation curve between irreducible water saturation and effective stress under different Poisson's ratio.

bundle of capillary in the minimum pore channel and the minimum pore channel size space is, and therefore, the irreducible water saturation is higher (Figure 9). Figure 10 shows the curves of relative permeability under different ratios of the maximum pore radius to the minimum pore radius. The smaller the ratio is, the greater the irreducible water saturation is, the more the isotonic point moves to 


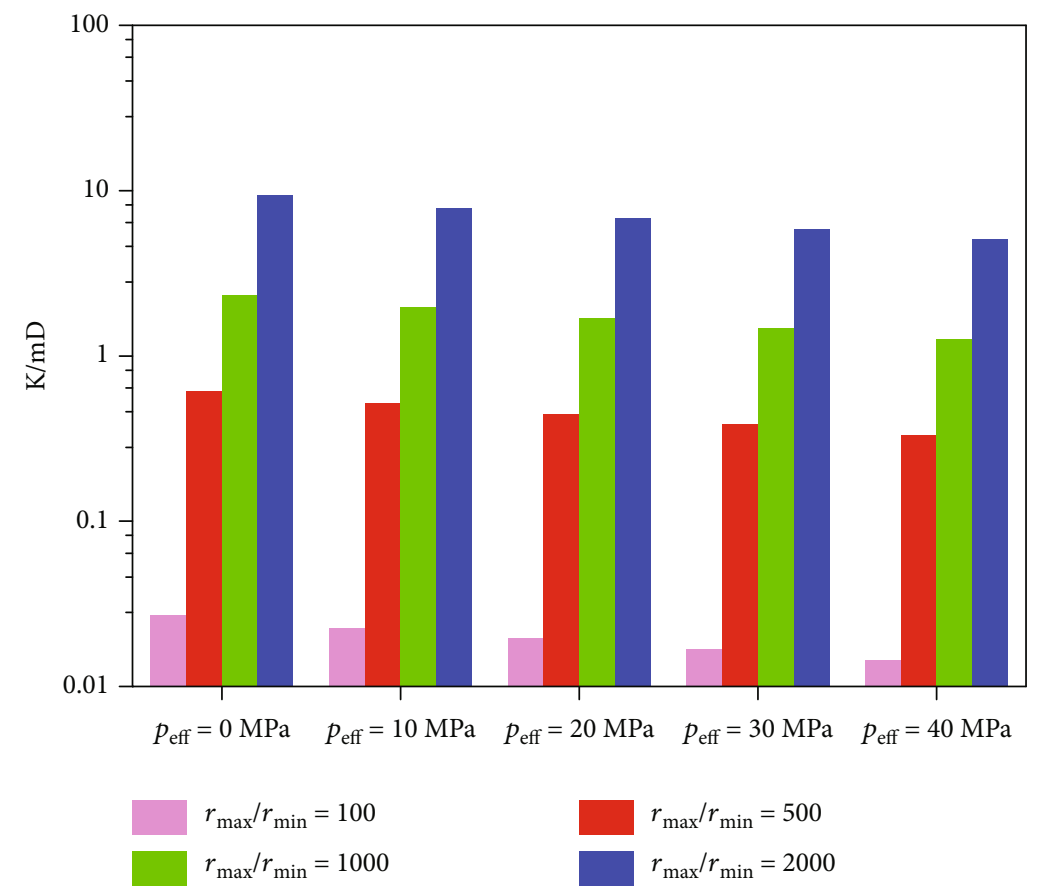

Figure 8: Permeability with different ratios of maximum pore radius to minimum pore radius.

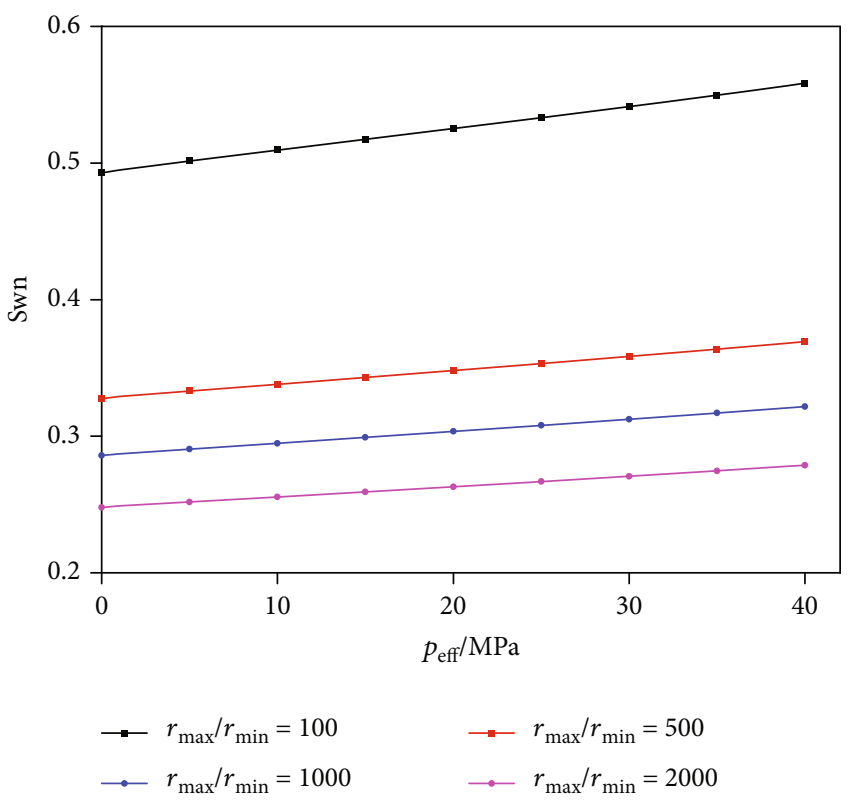

FIGURE 9: The relationship curve between irreducible water saturation and effective stress under different ratios of the maximum pore radius to the minimum pore radius.

the right direction, the smaller the two-phase flow interval is, and the worse the flow capacity is.

4.4. Minimum Flow Channel Radius. In the reservoir, the minimum flow channel radius is mainly controlled by the displacement pressure difference. The larger the displacement pressure is, the smaller the minimum flow channel radius is. When the effective stress is constant, the displace-

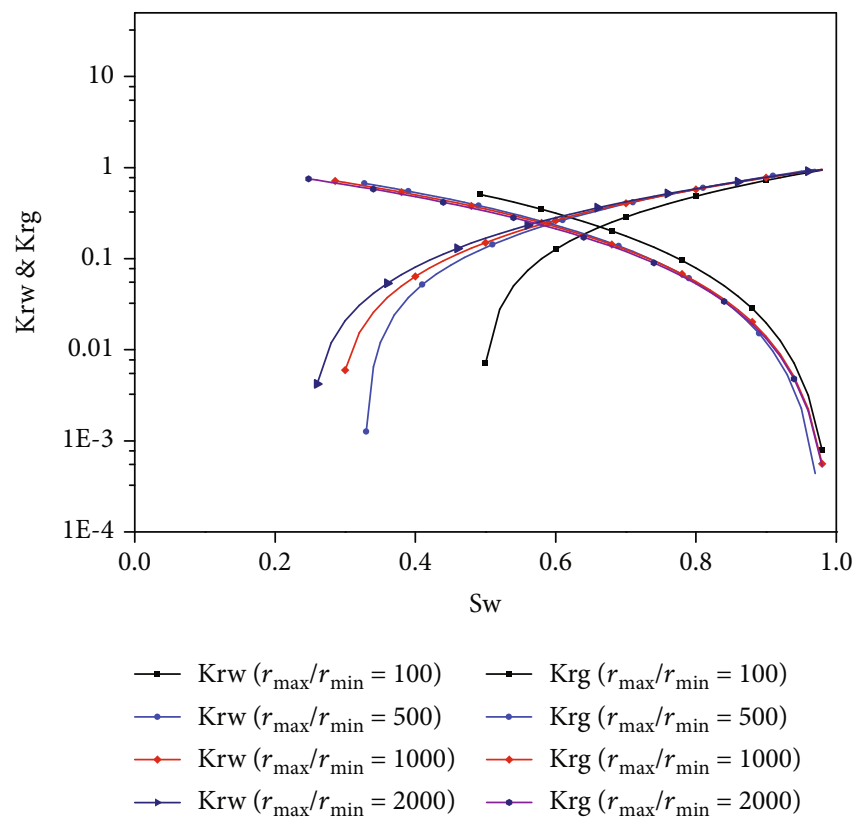

FIGURE 10: Curves of relative permeability under different ratios of the maximum pore radius to the minimum pore radius.

ment pressure has no effect on the permeability. Therefore, the minimum flow channel radius has no effect on the rock permeability. The radius of minimum flow channel is larger, the more capillary bundles do not flow, therefore, the irreducible water saturation is greater (Figure 11). While the effective stress increases, the capillary bundle becomes small. When the minimum flow channel radius is constant, the effective stress increases, and the irreducible water saturation 


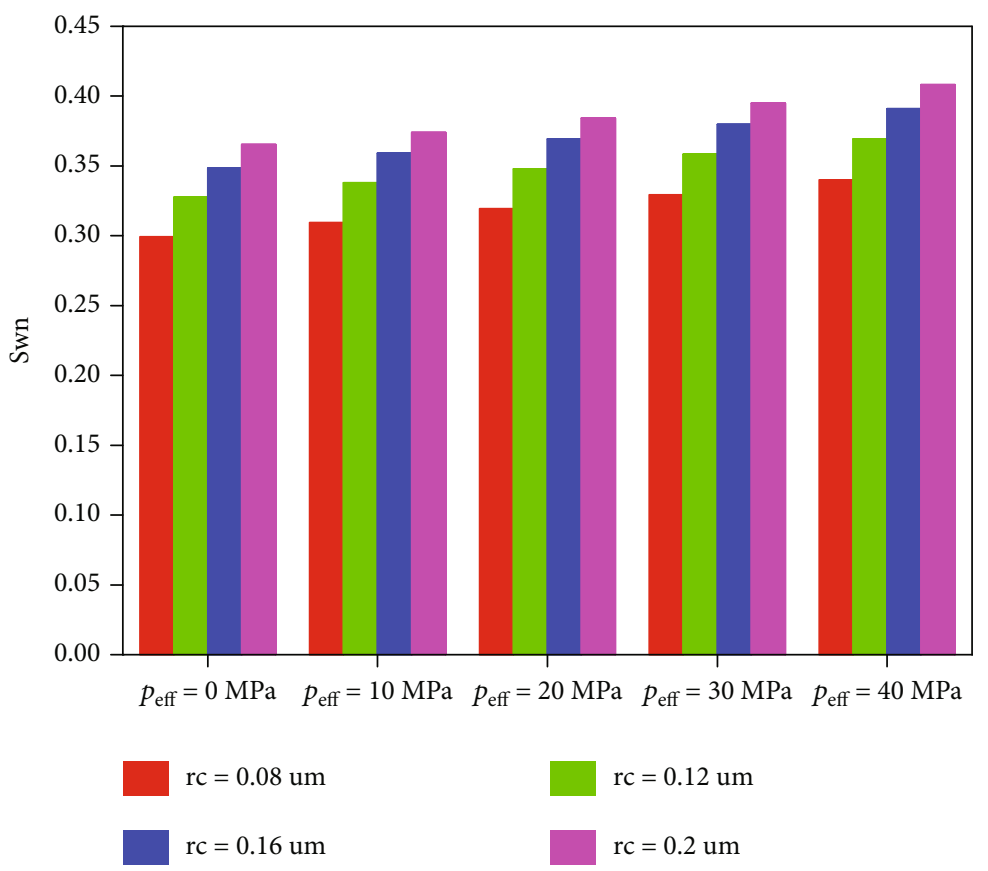

FIGURE 11: Irreducible water saturation under different minimum flow channel radius.

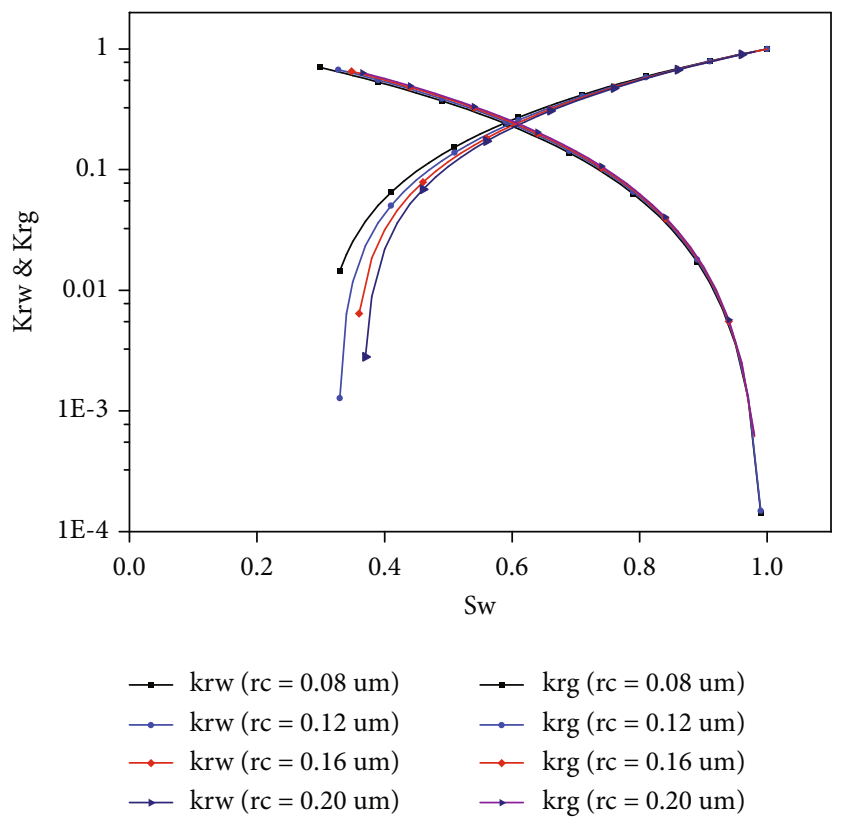

FIGURE 12: Relative permeability curves with different minimum flow channel radius.

increases. Figure 12 shows the two-phase relative permeability curves under different minimum flow channel radius. The smaller the minimum flow channel is, the greater the displacement pressure is, which mainly affects the twophase flow space of the relative permeability curve.

\section{Conclusion}

Based on capillary bundle model and fractal theory, the model of irreducible water saturation, the permeability model, and the relative permeability model are built in tight gas reservoirs, which can consider the effects of water film and stress sensitivity at the same time. The influence of some parameters is analyzed, which includes elastic modulus and Poisson's ratio on irreducible water saturation, core permeability, and relative permeability curves. Through above works, some conclusions can be drawn:

(1) Based on capillary bundle model and fractal theory, the model of irreducible water saturation, the permeability model, and the relative permeability model are constructed with the influence of irreducible water film and stress sensitivity. The above models can analyze some changes of irreducible water saturation, permeability, and relative permeability with formation pressure, which overcomes the fact that these parameters are regarded as pressure independent variables in most current studies

(2) As the elastic modulus of rock increases, the stresssensitive effect of reservoir is weakened. In the process of increasing effective stress, the increase in irreducible water saturation becomes smaller, the littler in permeability decreases, and the relative permeability curve does not change much

(3) Poisson's ratio has little influence on irreducible water saturation, stress sensitivity effect, and relative permeability curve

(4) When the porosity is constant and there are some large pores, the permeability increases significantly, the irreducible water saturation decreases significantly, and the two-phase flow interval increases. When the displacement pressure increases, the irreducible water saturation decreases 
(5) These models are only applicable to single porous media of reservoirs, and these application needs further research in fractured reservoirs

\section{Data Availability}

The data in this manuscript will be available upon the readers' request.

\section{Conflicts of Interest}

We declare that we have no competing interests.

\section{Acknowledgments}

This work was supported by the Open Foundation of State Key Laboratory of Shale Oil and Gas Enrichment Mechanisms and Effective Development (GSYKY-B09-32).

\section{References}

[1] W. S. Spencer, "Geologic aspects of tight gas reservoirs in the Rocky Mountain region," Journal of Petroleum Technology, vol. 37, no. 7, pp. 1308-1314, 1985.

[2] R. Rezaee, A. Saeedi, and B. Clennell, "Tight gas sands permeability estimation from mercury injection capillary pressure and nuclear magnetic resonance data," Journal of Petroleum Science \& Engineering, vol. 88-89, pp. 92-99, 2012.

[3] L. D. Sun, C. N. Zou, A. L. Jia et al., "Development characteristics and orientation of tight oil and gas in China," Petroleum Exploration and Development, vol. 46, no. 6, pp. 1015-1026, 2019.

[4] H. Q. Song, Y. Cao, M. X. Yu, Y. H. Wang, J. E. Killough, and J. Leung, "Impact of permeability heterogeneity on production characteristics in water- bearing tight gas reservoirs with threshold pressure gradient," Journal of Natural Gas Science and Engineering, vol. 22, pp. 172-181, 2015.

[5] H. Zhang, L. Wang, X. Wang et al., "Productivity analysis method for gas-water wells in abnormal overpressure gas reservoirs," Petroleum Exploration and Development, vol. 44, no. 2, pp. 280-285, 2017.

[6] Y. F. Meng, C. B. Luo, G. Li, and H. B. Liu, “An experimental study on stress sensitivity of tight sandstone gas reservoirs during nitrogen drilling," Arabian Journal of Geosciences, vol. 12, no. 18, pp. 576-586, 2019.

[7] A. P. S. Selvadurai, D. J. Zhang, and Y. L. Kang, "Permeability evolution in natural fractures and their potential influence on loss of productivity in ultra-deep gas reservoirs of the Tarim Basin, China," Journal of Natural Gas Science and Engineering, vol. 58, pp. 162-177, 2018.

[8] Y. Wang, L. Jeannin, F. Agostini, L. Dormieux, F. Skoczylas, and E. Portier, "Experimental study and micromechanical interpretation of the poroelastic behaviour and permeability of a tight sandstone," International Journal of Rock Mechanics and Mining Sciences, vol. 103, pp. 89-95, 2018.

[9] N. I. Christensen and H. F. Wang, "The influence of pore pressure and confining pressure on dynamic elastic properties of Berea sandstone," Geophysics, vol. 50, no. 2, pp. 207-213, 1985.

[10] F. O. Jones and W. W. Owens, "A laboratory study of lowpermeability gas sands," Journal of Petroleum Technology, vol. 32, no. 9, pp. 1631-1640, 1980.
[11] P. Guo, J. Zhang, J. F. Du, Y. G. Xu, and G. S. Wu, "Study on core stress sensitivity for gas reservoir with two experiment method," Journal of Southwest Petroleum university, vol. 29, no. 2, pp. 7-9, 2007.

[12] W. L. Xiao, M. Li, J. Z. Zhao, L. L. Zheng, and L. J. Li, "Laboratory study of stress sensitivity to permeability in tight sandstone," Rock and Soil Mechanics, vol. 31, no. 3, pp. 775-779, 2010.

[13] W. Xiao, T. Li, M. Li, J. Zhao, L. Zheng, and L. Li, "Evaluation of the stress sensitivity in tight reservoirs," Petroleum Exploration and Development, vol. 43, no. 1, pp. 115-123, 2016.

[14] P. F. Worthington, "The effect of scale on the petrophysical estimation of intergranular permeability," Petrophysics, vol. 45, no. 1, pp. 59-72, 2004.

[15] F. M. Tiller, "The role of porosity in filtration part I: numerical motheds," Chemical Engineering Progress, vol. 46, pp. 467479, 1953.

[16] R. W. Ostensen, "The effect of stress-dependent permeability on gas production and well testing," SPE Formation Evaluation, vol. 1, no. 3, pp. 227-235, 1986.

[17] Q. Lei, W. Xiong, C. Yuan, and Y. S. Wu, “Analysis of stress sensitivity and its influence on oil production from tight reservoirs," in Presented at the SPE Eastern Regional Meeting, pp. 17-19, Lexingto, Kentucky, 2007.

[18] N. Cao and G. Lei, "Stress sensitivity of tight reservoirs during pressure loading and unloading process," Petroleum Explorationand Development, vol. 46, no. 1, pp. 138-144, 2019.

[19] J. X. Xu, L. F. Yang, Y. H. Ding, Z. Liu, R. Gao, and Z. Wang, "Stress sensitivity analysis of the shalereservoir by the quartet structure generation set," Natural Gas Seoscience, vol. 30, no. 9, pp. 1341-1348, 2019.

[20] F. Civan and E. C. Donaldson, "Relative permeability from unsteady-state displacements with capillary pressure included," SPE Formation Evaluation, vol. 4, no. 2, pp. 189-193, 1989.

[21] J. C. Xu, C. H. Guo, R. Z. Jiang, and M. Z. Wei, "Study on relative permeability characteristics affected by displacement pressure gradient: experimental study and numerical simulation," Fuel, vol. 163, pp. 314-323, 2016.

[22] W. C. Yan, J. M. Sun, H. M. Dong, and L. K. Cui, "Investigating NMR-based absolute and relative permeability models of sandstone using digital rock techniques," Journal of Petroleum Science and Engineering, vol. 207, 2021.

[23] G. Lei, P. C. Dong, Z. S. Wu et al., "A fractal model for the stress-dependent permeability and relative permeability in tight sandstones," Journal of Canadian Petroleum Technology, vol. 54, no. 1, pp. 36-48, 2015.

[24] B. V. Derjaguin and N. V. Churaev, "Structural component of disjoining pressure," Journal of Colloid and Interface Science, vol. 49, no. 2, pp. 249-255, 1974.

[25] Y. L. Su, J. G. Fu, L. Li et al., "A new model for predicting irreducible water saturation in tight gas reservoirs," Petroleum Science, vol. 17, no. 4, pp. 1087-1100, 2020.

[26] P. Xu, S. Qiu, B. Yu, and Z. Jiang, "Prediction of relative permeability in unsaturated porous media with a fractal approach," International Journal of Heat and Mass Transfer, vol. 64, pp. 829-837, 2013.

[27] B. M. Yu, "Fractal character for tortuous streamtubes in porous media," Chinese Physics Letters, vol. 22, no. 1, pp. 158-160, 2005.

[28] B. M. Yu and J. H. Li, "A geometry model for tortuosity of flow path in porous media," Chinese Physics Letters, vol. 21, no. 8, pp. 1569-1571, 2004. 
[29] J. S. Yang and J. Y. Liu, Practical Calculation of Gas Production, Petroleum Industry Press, 2011.

[30] S. Gupta, R. Helmig, and B. Wohlmuth, "Non-isothermal, multi-phase, multi-component flows through deformable methane hydrate reservoirs," Computational Geosciences, vol. 19, no. 5, pp. 1063-1088, 2015.

[31] G. Lei, Z. Z. Dong, W. R. Li, Q. Z. Wen, and C. Wang, "Theoretical study on stress sensitivity of fractal porous media with irreducible water," Fractals, vol. 26, no. 1, 2017.

[32] Z. Harari, W. Shu-Teh, and S. Salih, "Pore-compressibility study of arabian carbonate reservoir rocks," SPE Formation Evaluation, vol. 10, no. 4, pp. 207-214, 1995.

[33] Y. K. Zhang, H. B. Luan, Y. G. Si, J. G. Wang, and W. Q. Wang, "The fundamental parameters determining method for the well test analysis in the waterflood reservoir," Well Testing, vol. 10, no. 6, pp. 23-25, 2001.

[34] K. W. Li and R. N. Horne, "Comparison of methods to calculate relative permeability from capillary pressure in consolidated water-wet porous media," Water Resources Research, vol. 42, no. 6, pp. 285-293, 2006.

[35] F. Mo, X. L. Peng, D. Devegowda et al., "Permeability jail for two-phase flow in tight sandstones: formulation, application and sensitivity studies," Journal of Petroleum Science and Engineering, vol. 184, 2020.

[36] M. L. Delli and J. Grozic, "Experimental determination of permeability of porous media in the presence of gas hydrates," Journal of Petroleum Science \& Engineering, vol. 120, pp. 1-9, 2014.

[37] K. Chen, H. Chen, and $\mathrm{P}$. Xu, "A new relative permeability model of unsaturated porous media based on fractal theory," Fractals, vol. 28, no. 1, article 2050002, 2020.

[38] C. D. Tsakiroglou, "A method to calculate the multiphase flow properties of heterogeneous porous media by using network simulations," AIChE Journal, vol. 57, no. 10, pp. 2618-2628, 2011.

[39] T. J. Miao, A. M. Chen, Y. Xu, S. J. Cheng, and K. D. Wang, “A permeability model for water-gas phase flow in fractal fracture networks," Fractals, vol. 26, no. 6, article 1850087, 2018.

[40] S. P. Ojha, S. Misra, A. Sinha et al., "Relative permeability and production-performance estimations for Bakken, Wolfcamp, Eagle Ford, and Woodford shale formations," SPE Reservoir Evaluation \& Engineering, vol. 28, no. 2, pp. 307-324, 2018. 